BAHAR TAŞAR, M.Eng. ${ }^{1}$

E-mail: bahar.turantasar@gmail.com

DENIZ TÜRSEL ELiiYi, Ph.D. ${ }^{2}$

(Corresponding author)

E-mail: deniz.eliiyi@bakircay.edu.tr

LEVENT KANDILLER, Ph.D. ${ }^{3}$

E-mail: levent.kandiller@yasar.edu.tr

${ }^{1}$ Ege University

Faculty of Economics and Administrative Sciences

Department of Business Administration

35100, Bornova, İzmir, Turkey

2 Izmir Bakircay University

Faculty of Engineering and Architecture

Department of Industrial Engineering

35665, Menemen, İzmir, Turkey

${ }^{3}$ Yaşar University, Faculty of Engineering

Department of Industrial Engineering

35100, Bornova, İzmir, Turkey
Traffic Management Original Scientific Paper Submitted: 24 July 2017 Accepted: 21 Jan. 2019

\title{
VEHICLE ROUTING WITH COMPARTMENTS UNDER PRODUCT INCOMPATIBILITY CONSTRAINTS
}

\begin{abstract}
This study focuses on a distribution problem involving incompatible products which cannot be stored in a compartment of a vehicle. To satisfy different types of customer demand at minimum logistics cost, the products are stored in different compartments of fleet vehicles, which requires the problem to be modeled as a multiple-compartment vehicle routing problem (MCVRP). While there is an extensive literature on the vehicle routing problem (VRP) and its numerous variants, there are fewer research papers on the MCVRP. Firstly, a novel taxonomic framework for the VRP literature is proposed in this study. Secondly, new mathematical models are proposed for the basic MCVRP, together with its multiple-trip and split-delivery extensions, for obtaining exact solutions for small-size instances. Finally, heuristic algorithms are developed for larger instances of the three problem variants. To test the performance of our heuristics against optimum solutions for larger instances, a lower bounding scheme is also proposed. The results of the com putational experiments are reported, indicating validity and a promising performance of an approach.
\end{abstract}

\section{KEY WORDS}

multiple-compartment vehicle routing problem; incompatible products; split delivery; multiple trips; mathematical model; heuristic algorithms;

\section{INTRODUCTION}

The vehicle routing problem (VRP) arises from the logistics field and deals with the distribution of goods to customers [1]. It is a generalization of the traveling salesman problem (TSP), which is an NP-hard problem [2]. The concept of a multiple-compartment VRP
(MCVRP) includes separated compartments carrying incompatible products requested by one or more customers. The problem aims to meet different types of customer demands in the same vehicle while seeking minimum distribution cost. There is an extensive literature on routing problems which includes taxonomic studies [3-7]. Figure 1 proposes a new taxonomy for the VRP.

The general VRP can be represented using six main classes with respect to constraints describing the problem structure, those being operational policy, objective, vehicle, product, depot and period. The operational policy dimension represents problem characteristics and constraints regarding system configuration and operating principles. In the VRP, soft time windows (STW) [8] or hard time windows (HTW) [9] can be defined to determine operational constraints while servicing each node. Another operational classification identifies the problem as pickup and delivery (PD) [10], backhaul (BH) [11] or backhaul and linehaul (BH\&LH) [12], as opposed to the classical linehaul problems. If the demand of a customer can be satisfied by more than one vehicle, the VRP with split delivery (SLD) [13] is valid; otherwise, no split deliveries are allowed. The last operational classification category divides the problem as a single-trip (ST) or multi-trip (MT) VRP [14], allowing a vehicle to perform one or several trips within the planning period. The VRPs also differ according to their desired objectives. Literature widely uses minisum objectives, which minimize the total distribution cost (MSTC) [15], total distribution time (MSTT) [16] or total length of routes (MSTL). Minimizing the total waiting time of the customers (MSWT) [17] is 

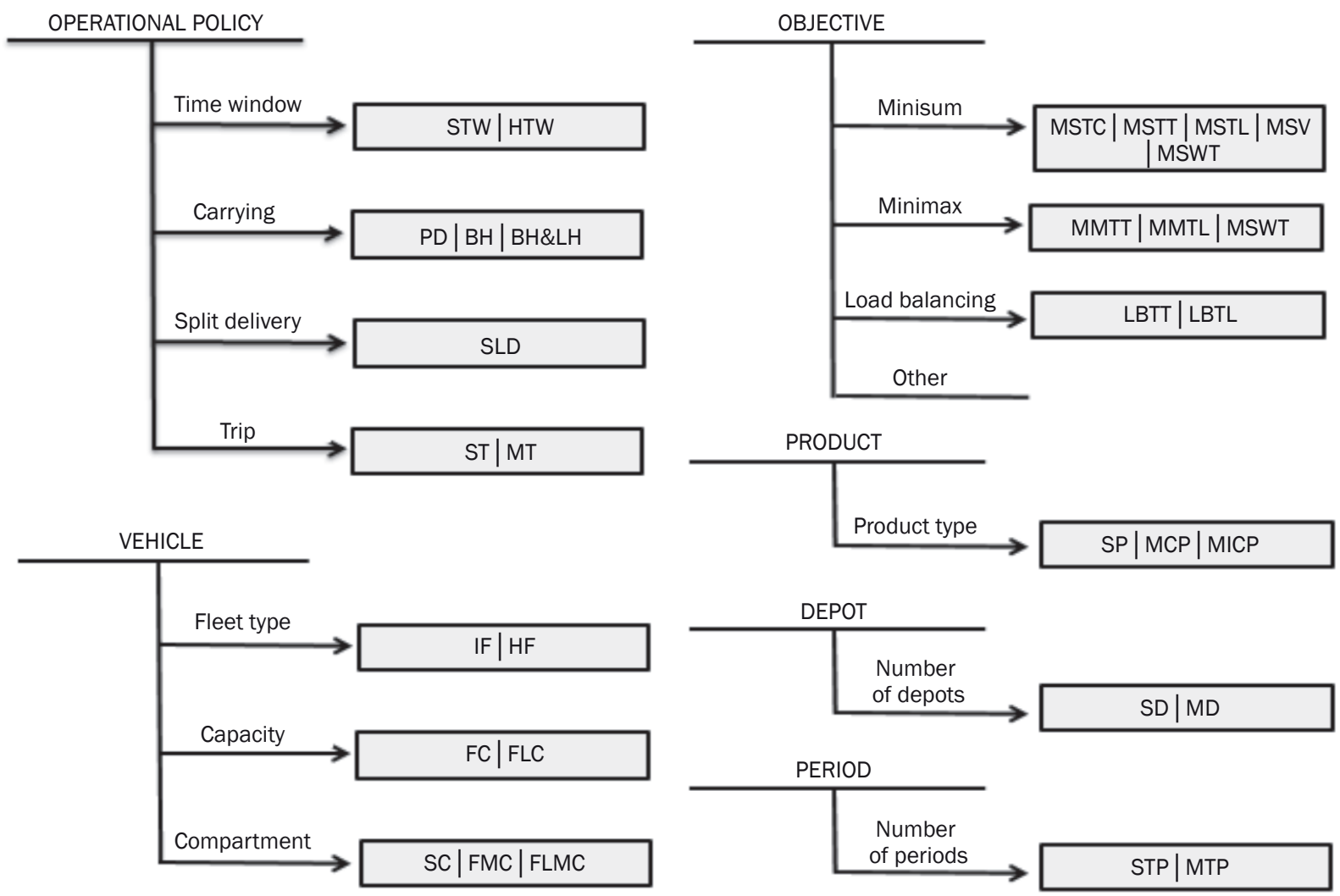

Figure 1 - VRP taxonomy

another objective considered for representing customer satisfaction. Minimax objectives, such as minimizing the maximum travel time (MMTT) [18] or travel length (MMTL) [19], can be useful in balancing the workload of drivers, and explicit load balancing objectives (LBTT and LBTL) $[20,21]$ can be used for the same purpose. Depending on the problem structure, other objectives can also be considered, such as non-monetary objectives in humanitarian logistics problems [22].

In vehicle dimension, depending on the type of vehicle, the fleet can be identical (IF) or heterogeneous (HF) [23]. In terms of capacity restrictions of the vehicles in the fleet, the most studied problem is fixed capacity (FC), where vehicle number and capacity are assumed to be predetermined and cannot be altered. In contrast, the number of vehicles or their capacities can be increased in the flexible fleet size (FLC) category [24]. In terms of compartments, the vehicles may have a single compartment (SC), fixed-size multiple compartments (FMC) or flexible-size multiple compartments (FLMC) [25]. It should be noted that compartment size flexibility does not necessarily bring flexibility to vehicle capacity; total vehicle capacity may be fixed while allowing flexible compartments. For other dimensions, the distribution problem may involve a single product (SP) or multiple compatible (MCP) or incompatible (MICP) products. The depots in the problem may be single (SD) or multiple (MD) [26]. Finally, the planning horizon of the problem may involve a single time period (STP), which is mostly the case, or multiple time periods (MTP) [27]. Our taxonomy is inspired by Kendall's notation [28]. The notation, including one segment for each dimension and subsegments separated by commas, is illustrated in Figure 2 .

Recent MCVRP studies are listed in Table 1 using our taxonomy. Lahyani et al. [15] studied the collection of olive oil using heterogeneous multiple-compartment vehicles with split delivery for different types of products. They solved the problem using a branch-and-cut algorithm. Coelho and Laporte [37] described the MCVRP for fuel distribution, which distinguishes between split and unsplit compartments and tanks. They proposed two mixed integer linear programming formulations and a branch-and-cut algorithm for all problem variants. Since the MCVRP is an NP-Hard problem, most studies use heuristic

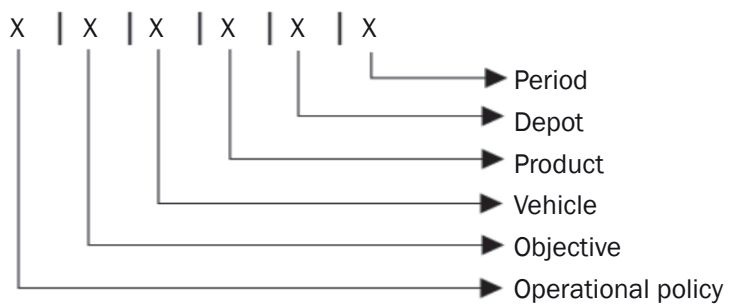

Figure 2 - Proposed notation 
Table 1 - Recent MCVRP literature

\begin{tabular}{|c|c|c|c|c|c|c|c|}
\hline Authors & Year & & & Problem & & & \\
\hline Van der Bruggen et al. [29] & 1995 & ST & I МMTC & I HF, FC, FMC & I MICP & I SD & I STP \\
\hline Avella et al. [30] & 2004 & ST & | MMTL & I IF, FC, FMC & I MICP & I SD & | STP \\
\hline Suprayogi et al. [31] & 2006 & SLD, MT & I MSV, MMTT, LBTT & I IF, FC, FMC & I MICP & I SD & I STP \\
\hline El Fallahi et al. [32] & 2008 & SLD, ST & | MMTL & I IF, FLC, FMC & I MICP & ISD & I STP \\
\hline Mendoza et al. [33] & 2010 & ST & | MMTL & I IF, FLC, FMC & I MICP & ISD & I STP \\
\hline Derigs et al. [25] & 2011 & ST & | MMTL & I IF, FC, FMC & I MICP & ISD & | STP \\
\hline Surjandari et al. [34] & 2011 & SLD, ST & | MMTL & I HF, FC, FMC & I MICP & I MD & | MTP \\
\hline Benantar and Oufi [35] & 2012 & TW, ST & | MMTL & I HF, FC, FMC & I MICP & SD & | STP \\
\hline Asawarungsaengkul et al. [36] & 2013 & SLD, ST & | MMTL & I HF, FC, FMC & I MICP & $\mathrm{SD}$ & I STP \\
\hline Lahyani et al. [15] & 2015 & SLD, ST & I MSV, MMTL & I HF, FC, FMC & I MICP & ISD & I MTP \\
\hline Coelho and Laporte [37] & 2015 & SLD, ST & I MSTC & I IF, FC, FMC & I MICP & ISD & | MTP \\
\hline Abdulkader et al. [38] & 2015 & ST & I MSTC & I IF, FC, FMC & I MICP & ISD & I STP \\
\hline Koch et al. [39] & 2016 & ST & I MSTC & I IF, FC, FLMC & I MICP & ISD & I STP \\
\hline Rabbani et al. [26] & 2016 & ST & I MSTC & I HF, FC, FLMC & I MICP & | MD & I STP \\
\hline Alinaghian and Shokouhi [40] & 2017 & SLD, ST & I MSV, MSTL & I IF, FC, FMC & | MICP & I MD & STP \\
\hline
\end{tabular}

algorithms to solve the problem and its variants. For instance, El Fallahi et al. [32] proposed a memetic algorithm as a genetic algorithm hybridized with a local search procedure for constructive heuristics and a tabu search [45] for path relinking. Abdulkader et al. [38] introduced a distance-constrained variant of the problem by applying a hybrid ant colony optimization algorithm and local search procedures. Koch et al. [39] worked on the MCVRP with flexible compartment sizes and developed a genetic algorithm where each gene represents a customer location and their supply of a specific product type. The initial population was generated by a completely randomized procedure and savings method [43]. They used swap and insertion algorithms for mutations. Rabbani et al. [26] considered a distance-constrained variant of the MCVRP with heterogeneous vehicles, multiple depots and mixed open and closed tours, proposing a mathematical formulation based on genetic algorithms as metaheuristics for the solution. Genetic algorithms were used for initial solutions and the iterative swap procedure [44] was used for the improvement phase. Alinaghian and Shokouhi [40] introduced the MCVRP under multiple depot and split delivery assumptions. The authors developed a mathematical model and a hybrid algorithm, composed of an adaptive large neighborhood search and a variable neighborhood search for large scale instances.

Our study derives its roots from a real-life VRP of a local feed distributor. The basic VRP and its multitrip extension was modeled in an earlier study [41]. As the problem is clearly NP-hard, pilot experimentation revealed that only small-size instances could be solved to optimality within acceptable CPU times. The authors stressed the need for heuristic approaches for larger practical instances, although no such approach was presented.

In the next section, we adapt the basic MCVRP model [41] with a modification in the subtour elimination constraints for ST | MSTC | IF,FC,FMC | MICP | SD | STP. We then propose multiple-trip (MT | MSTC | IF,FC,FMC | MICP | SD |STP) and split-delivery (SLD | MSTC | IF,FC,FMC | MICP | SD| STP) extensions for constructing other acceptable routing alternatives for a feed distributer. Since the problem increases in practical applications, we propose heuristic approaches and lower bounds for all three variants in Section 3. Comprehensive computational results, including both exact and heuristic performances, are presented in Section 4. Section 5 includes our conclusions and future research directions.

\section{FORMULATION}

In this section, mathematical formulations of the problem are presented. The basic model, adapted from [41], is presented in Section 2.1, while multiple-trip and split-delivery extensions are presented in Section 2.2.

\subsection{The basic model}

The basic problem modeled in this section does not allow a split delivery or multiple trips, represented as ST | MSTC | IF,FC,FMC | MICP | SD | STP. Identical vehicles are available and fully loaded at the single depot at the start of the planning period. An 8-hour shift is assumed for all vehicles. Each compartment of a vehicle is dedicated to a single type of product due to 
product incompatibility. Loading and unloading times are included in the traveling time. Each customer orders one type of product and, since there is no split delivery, the customer demand cannot exceed the vehicle capacity. The parameters and decision variables are defined below:

$f_{k} \quad$ - fixed cost for vehicle $k$ (USD), $k=1, \ldots, K$

$C_{l k}$ - capacity of compartment $l$ of vehicle $k$ [tons], $l=1, \ldots, L, k=1, \ldots, K$

$D_{i p}$ - demand of customer $i$ for product type $p$ [tons], $i=1, \ldots, N, p=1, \ldots, P$

$s_{i j}$ - distance from customer $i$ to customer $j[\mathrm{~km}]$, $i, j=1, \ldots, N$

$\propto \quad$ - fuel cost [USD/km]

$T_{k}$ - time capacity of vehicle $k$ [min], $k=1, \ldots, K$

$T_{i j}$ - time from customer $i$ to customer $j$ [min], $i, j=1, \ldots, N$

$x_{k i}=\left\{\begin{array}{l}1, \text { if vehicle } k \text { serves customer } i \\ 0, \text { otherwise }\end{array}\right.$ $k=1, \ldots, K, i=1, \ldots, N$

$y_{k}=\left\{\begin{array}{l}1, \text { if vehicle } k \text { is used } \\ 0, \text { otherwise }\end{array}, k=1, \ldots, K\right.$

$u_{i j}=\left\{\begin{array}{l}1, \text { if route from customer } i \text { to customer } j \text { is used } \\ 0, \text { otherwise }\end{array}\right.$ $i, j=1, \ldots, N$

$z_{i}=\left\{\begin{array}{l}1, \text { if route from depot to customer } i \text { is used } \\ 0, \text { otherwise }\end{array}\right.$ $i=1, \ldots, N$

$v_{i}=\left\{\begin{array}{l}1, \text { if route from customer } i \text { to depot is used } \\ 0, \text { otherwise }\end{array}\right.$ $i=1, \ldots, N$

$a_{l k p}=\left\{\begin{array}{c}1, \text { if compartment } l \text { of vehicle } k \text { is used for } \\ \quad \text { product type } p \\ \text { 0, otherwise }\end{array}\right.$ $l=1, \ldots, L, k=1, \ldots, K, p=1, \ldots, P$

$t_{i j}^{k} \quad$ - time taken by vehicle $k$ from customer $i$ to customer $j, k=1, \ldots, K, i, j=1, \ldots, N$

The mathematical model formulation is as follows:

$\operatorname{Min} \sum_{k=1}^{K} f_{k} y_{k}+\alpha\left\{\sum_{i=1}^{N}\left[\left(s_{i 0} v_{i}\right)+\left(s_{0 i} z_{i}\right)+\sum_{j=1}^{N}\left(s_{i j} u_{i j}\right)\right]\right\}$

Subject to:

$$
\begin{aligned}
& \sum_{i=1}^{N} x_{k i} \leq N y_{k} \quad \forall k=1, \ldots, K \\
& \sum_{i=1}^{N} D_{i p} x_{k i} \leq \sum C_{l k} a_{l k p} \quad \forall k=1, \ldots, K ; p=1, \ldots p \\
& \sum_{p=1}^{P} a_{l k p} \leq y_{k} \quad \forall l=1, \ldots, L ; k=1, \ldots, K \\
& \sum_{k=1}^{K} x_{k i}=1 \quad \forall i=1, \ldots, N \\
& z_{j}+\sum_{i=1}^{N} u_{i j}=1 \quad \forall j=1, \ldots, N ; i \neq j
\end{aligned}
$$

$$
\begin{aligned}
& v_{i}+\sum_{i=1}^{N} u_{i j}=1 \quad \forall i=1, \ldots, N ; i \neq j \\
& \sum_{i=1}^{N} z_{i}=\sum_{k=1}^{K} y_{k} \\
& \sum_{i=1}^{N} v_{i}=\sum_{k=1}^{K} y_{k} \\
& x_{k i}-\left(1-u_{i j}\right) \leq x_{k j} \quad \forall k=1, \ldots, K ; i, j=1, \ldots, N ; i \neq j \\
& x_{k j}-\left(1-u_{i j}\right) \leq x_{k i} \quad \forall k=1, \ldots, K ; i, j=1, \ldots, N ; i \neq j \\
& t_{i j}^{k} \geq T_{i j}-T_{i j}\left(2-x_{k i}-u_{i j}\right) \\
& \forall k=1, \ldots, K ; i, j=1, \ldots, N ; i \neq j \\
& t_{0 j}^{k} \geq T_{0 j}-T_{0 j}\left(2-x_{k i}-z_{j}\right) \forall k=1, \ldots, K ; i, j=1, \ldots, N \\
& t_{i 0}^{k} \geq T_{i 0}-T_{i 0}\left(2-x_{k i}-v_{i}\right) \forall k=1, \ldots, K ; i, j=1, \ldots, N \\
& \sum_{k=1}^{K} t_{i j}^{k} \leq T_{i j} u_{i j} \quad \forall i, j=1, \ldots, N ; i \neq j \\
& \sum_{k=1}^{K} t_{0 j}^{k} \leq T_{0 j} z_{j} \quad \forall j=1, \ldots, N \\
& \sum_{k=1}^{K} t_{i 0}^{k} \leq T_{i 0} v_{i} \quad \forall i=1, \ldots, N \\
& \sum_{j=1}^{N} t_{0 j}^{k}+\sum_{i=1}^{N} t_{i 0}^{k}+\sum_{i=1}^{N} \sum_{j=1}^{N} t_{i j}^{k} \leq T_{k} \quad \forall k=1, \ldots, K \\
& u_{i j}+u_{j i} \leq 1 \quad \forall i, j=1, \ldots, N ; i \neq j \\
& u_{i j}+u_{j i}+u_{i m}+u_{j m}+u_{m i}+u_{m j} \leq 2 \\
& \forall i, j, m=1, \ldots, N ; i \neq j \neq m \\
& x_{k i}, y_{k}, z_{i}, v_{i}, u_{i j} \in\{0,1\} \forall k=1, \ldots, K ; i, j=1, \ldots, N ; i \neq j \\
& a_{l k p} \in\{0,1\} \quad \forall l=1, \ldots, L ; k=1, \ldots, K ; p=1, \ldots, P \\
& t_{i j}^{k}, t_{0 j}^{k}, t_{i 0}^{k} \geq 0 \quad \forall k=1, \ldots, K ; i, j=1, \ldots, N ; i \neq j
\end{aligned}
$$

The Objective Function 1 minimizes the sum of the fixed vehicle cost and the fuel cost. A vehicle can serve customers only if it is in use (2). Capacity restrictions are enforced through Constraint 3, while Constraint 4 ensures one type of product in each compartment/ silo. Each customer can be served by only one vehicle; hence, no split deliveries are allowed, which is described by Constraint 5. Constraints 6 and 7 satisfy the flow balance of vehicles' routes, while 8 and 9 ensure that the entrance and exits to/from the depot are equal to the total number of vehicles used. Continuity of routes is guaranteed through Constraints 10 and 11 . Constraints 12-14 calculate travel times for feasible routes. Time and route variables are linked through Constraints 15-17. Constraint 18 guarantees time-feasible routes in terms of the 8 -hour vehicle shifts. Constraints 21-23 define the values of decision variables as binary or real non-negative.

We replace the all-subtour elimination constraint that was used in the model presented in the paper [41] with Constraints 19 and 20, which are subtour 
elimination constraints that include only 2-node and 3-node subtours. Our initial numerical experiments show that these constraints eliminate the majority of the resulting subtours at a small computational cost. Therefore, we included only these constraints in the model, as opposed to the highly time-consuming one used in [41]. Further subtour constraints for four or more customers are added to the model whenever subtours appear in the optimal solution, which will be explained in Section 4.

\subsection{Multiple trips and split delivery}

The multiple-trip extension of the problem is denoted as MT | MSTC | IF,FC,FMC | MICP | SDISTP based on our taxonomy. This extension allows a maximum of $\mathrm{R}$ trips per vehicle during the working day. A trip index is defined as $r=1, \ldots, R$, and the number of vehicles in the model is replaced by $k=1, \ldots, K, K+1, \ldots, 2 K, \ldots, 2 K+1, \ldots, R K$. With this representation, indices $K+1, \ldots, 2 K$ denote the $2^{\text {nd }}$ trip of the $K$ vehicles, $2 K+1, \ldots, 3 K$ denote the $3^{\text {rd }}$ trip, etc. Constraint 24 then ensures that a vehicle can make its next tour only if it performs its previous one. To satisfy the time constraint for a vehicle performing multiple trips, Constraint 18 is replaced by $18^{\prime}$ in the model.

$$
\begin{aligned}
& y_{r K+k} \leq y(r-1) K+k \quad \forall k=1, \ldots, K ; r=1, \ldots, R \\
& \sum_{r=1}^{R} \sum_{j=1}^{N} t_{0 j}^{(r-1) K+k}+\sum_{r=1}^{R} \sum_{i=1}^{N} t_{i 0}^{(r-1) K+k}+ \\
& +\sum_{r=1}^{R} \sum_{i=1}^{N} \sum_{j=1}^{N} t_{i j}^{(r-1) K+k} \leq T_{k} \\
& \forall k=1, \ldots, K
\end{aligned}
$$

When split delivery is allowed, the problem becomes SLD | MSTC | IF,FC,FMC | MICP | SD| STP. A customer's demand can be met through a delivery by several vehicles, hence, Constraint 5 needs to be omitted from the model. A vehicle index is added to decision variables $u, z$ and $v$, and Constraints 6 and 7 are modified as stated below. Constraint 25 is added to ensure flow balance. Another change handles fulfillment of a customer's demand through a new continuous non-negative decision variable $q_{k i}$ between 0 and 1 , representing the percentage of customer $i$ 's demand met by vehicle $k$. Constraint 3 is then replaced by 3 ' to accommodate this change. Constraint 26 ensures that a vehicle can satisfy a demand percentage of a customer only if it visits that customer. Demand of each customer is met via the additional Constraint 27 , and the new decision variable is defined by Constraint 28 . Constraints 15-17 are also updated to handle relations between vehicle visits and time used. The modified constraints are listed below.

$$
z_{k j}+\sum_{i=1}^{N} u_{k i j}=x_{k j} \quad \forall k=1, \ldots, K ; i=1, \ldots, N ; i \neq j
$$

$$
\begin{aligned}
& v_{k i}+\sum_{i=1}^{N} u_{k i j}=x_{k i} \quad \forall k=1, \ldots, K ; i=1, \ldots, N ; i \neq j \\
& \sum_{i=1}^{N} u_{k j i}+v_{k i}=\sum_{i=1}^{N} u_{k i j}+z_{k j} \\
& \forall k=1, \ldots, K ; j=1, \ldots, N ; i \neq j \\
& \sum_{i=1}^{N} D_{i p} q_{k i} \leq \sum_{l=1}^{L} C_{l k} a_{l k p} \quad \forall k=1, \ldots, K ; p=1, \ldots, p \\
& q_{k i} \leq x_{k i} \quad \forall k=1, \ldots, K ; i=1, \ldots, N \\
& \sum_{k=1}^{K} q_{k i}=1 \quad \forall i=1, \ldots, N \\
& q_{k i} \geq 0 \quad \forall k=1, \ldots, K ; i=1, \ldots, N \\
& t_{i j}^{k} \leq T_{i j} u_{k i j} \quad \forall i, j=1, \ldots, N ; i \neq j \\
& t_{0 j}^{k} \leq T_{0 j} z_{k j} \quad \forall j=1, \ldots, N \\
& t_{i 0}^{k} \leq T_{i 0} v_{k i} \quad \forall i=1, \ldots, N
\end{aligned}
$$

\section{SOLUTION APPROACH}

The MCVRP model and its two extensions are solved to optimality for small-size test problems, using IBM ILOG CPLEX 12.6. While obtaining optimal solutions, subtours including four or more customers are checked after obtaining the initial optimal solution, and further necessary subtour elimination constraints are added as cuts to the initial model. For the basic model, optimal solutions could not be obtained within reasonable computation times for instances of 20 or more customers. For multiple-trip and split-delivery extensions, even a group of 15 customers was large enough for obtaining exact solutions. Therefore, the heuristic approaches for the basic, multiple-trip and split-delivery variants are developed and explained in the following subsections.

\subsection{Construction and improvement heuristics}

In the construction heuristics for the basic problem, the customers are selected in a random manner and assigned to the same vehicle, as long as there is enough capacity. If no more customers can be assigned to the same vehicle, a new vehicle is opened to be used. The construction procedure continues until all customers' demands are assigned to vehicles. The vehicles visit the customers in the order they are assigned, hence, an initial route for each vehicle is formed automatically as the assignments are being made. Our improvement phase starts with a modified variable neighborhood search (mVNS) algorithm, which consists of swap and insertion moves to improve the initial route of each vehicle shown in Figure 3.

A VNS is based on the systematic change of the neighborhood during the search [42]. A greedy remove/insert type heuristic with an mVNS substage is 


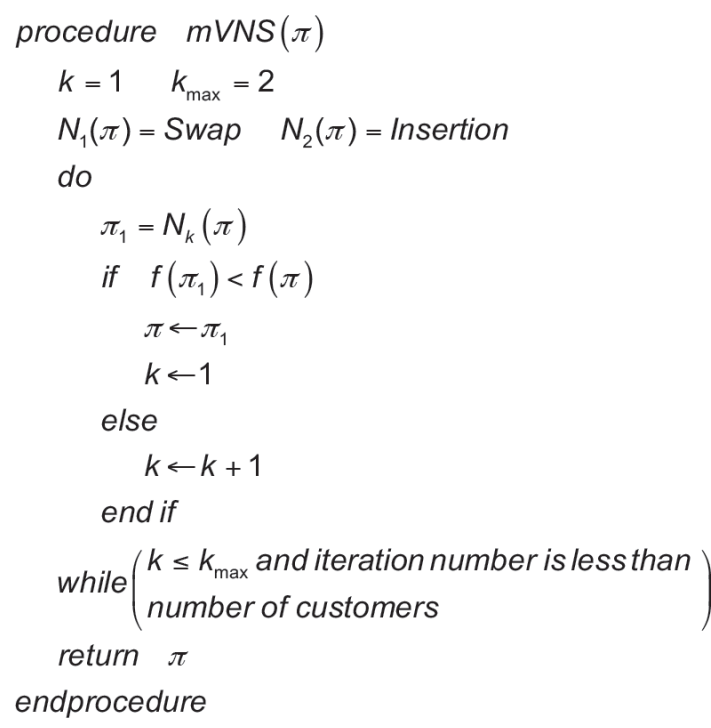

Figure 3 - Procedure for mVNS

used subsequently. For this purpose, the vehicles are sorted in an increasing order according to their total capacities. The first customer's demand is removed from the first vehicle. Then, starting with the last vehicle and moving towards the first, the algorithm checks whether the remaining capacity is sufficient (for the same type of product) for inserting the removed demand. If there is such a vehicle, the initial and the changed route costs are calculated for both vehicles. The switch is performed if there is a saving in cost and the remaining capacities of the vehicles are updated. The routes of both vehicles are then improved through the mVNS algorithm as the visited nodes are changed. The displacement starts from the first customer of the first vehicle, and the procedure tries to find room in the last vehicle. Since it is not easy to empty a vehicle loaded to its maximum capacity, the aim of the algorithm is to maximize the total amount of demands served by that vehicle, with the hope of reducing the number of vehicles used. The algorithm continues with the next customer of the first vehicle in the same manner. After all the customers that could be removed are processed, total savings are computed. It should be noted that the fixed cost of an emptied vehicle is also included in the savings if all its customers can be moved to other vehicles. The improvement procedure described above is outlined in Figure 4.

The solution approach for the multiple-trip problem is the same as for the basic model, with the additional consideration of multiple trips per day. Hence, to completely remove a vehicle from the schedule and eliminate its fixed cost, all trips of the same vehicle should be empty. In the case of a split delivery, one or two vehicles can meet a customer's demand. Due to practical considerations, the percentage of a customer's demand served by any vehicle should be greater than a threshold, which is called a minimum splitting ratio.
The solution approach has similar construction and improvement steps, but the algorithm also considers possible ways of demand splitting and assigning each portion to a different vehicle. This assumption considerably increases the complexity of the algorithm.

\subsection{Lower bounds}

We were able to show the efficiency of our heuristic results for small-size instances by comparing them with the optimal values. Since the problem is NP-hard, in order to test our heuristic model for large-size problem instances, we need to compute some lower bound values of the objective function. Three lower bounds are developed for the problem. For the base model, a lower bound on total fixed cost is computed by multiplying the total number of vehicles with the fixed cost of a vehicle. To find a bound for the number of vehicles, the total amount of demands for each type of product $\left(\sum_{i} D_{i p} ; i\right.$ :customers, $p$ : product type $)$ is divided by the compartment capacity $(C)$ and the upper bound integer value is taken as the number of compartments needed for a certain product type. The total number of compartments needed for all products $\left(\sum_{p}\left\lceil\frac{\sum_{i} D_{i p}}{C}\right\rceil\right)$ is then divided by the number of compartments that can fit on vehicles (four in practice), giving a bound on the total number of required vehicles:

\#Vehicles $=\left\lceil\frac{\sum_{p}\left\lceil\sum_{i} D_{i p} / C\right\rceil}{\# \text { Compartments }}\right\rceil$

For the multiple-trip extension, a maximum of two trips is assumed per vehicle per day as a reasonable and practical assumption. Hence, a lower bound on the number of needed vehicles is found by dividing the number of vehicles found above by two and taking the integer upper. For the split-delivery model, lower bound is the same as the base model. There are three different lower bounding methods for the routing cost, as explained below.

LB1: The first bound tries to find the minimum distribution distance by seeking customers' neighbors and by forming clusters equal to the lower bound on the number of vehicles (computed as above). The procedure starts with node 1 and selects two of its nearest customers. This is applied to each node, so that each customer is connected to its two closest neighbors. Repetitions are removed; if a customer appears in more than two clusters, only the minimum two distances for that customer are kept while the rest are erased. The next step is to enforce depot connection arcs. The number of entrances/exits from/to depot should be equal to the bound of the number of vehicles. For each vehicle, the nearest customers from the depot are selected as tour start nodes. Selected customers' previous connections are removed and they 


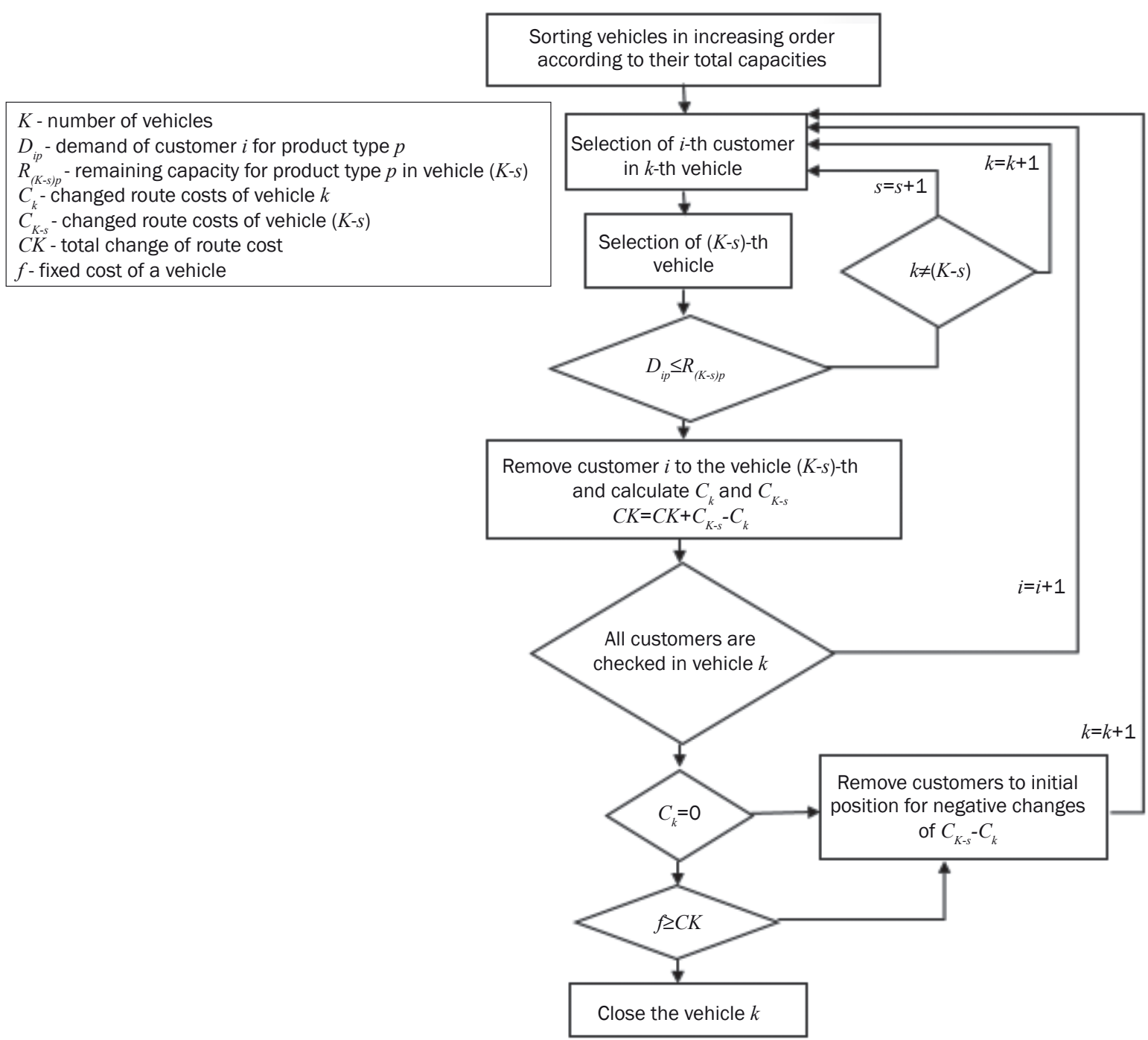

Figure 4 - Flowchart of the improvement phase

are connected to depot. The sum of all arc distances is multiplied by the fuel cost, providing a lower bound for total route cost.

LB2: A second lower bound is obtained by solving an assignment problem without depot and subtour elimination constraints to optimality using CPLEX. This bound provides an optimal customer-vehicle assignment while ignoring feasible tours. To add the depot connections on the assignment solution, we follow the same procedure as in LB1.

LB3: The last lower bound is obtained by solving the original model with a 5-minute computational time limit.

\section{NUMERICAL RESULTS}

A computational study is carried out to evaluate the performance of our mathematical formulation and heuristic algorithms. In Table 2, the parameters and their levels used in numerical tests are listed.
Table 2 - Factors and Levels

\begin{tabular}{||l|c||}
\hline \multicolumn{1}{|c|}{ Factors } & Levels \\
\hline \hline \# of customers $(N)$ & $10,15,20,50,100$ \\
\hline Demand & U[1,8], U[1,16], U[4,12] \\
\hline Fixed cost & USD 200, USD 400 \\
\hline
\end{tabular}

Number of customers $(N)$ directly affects the problem size and its levels are determined as 10 , 15, 20, 50 and 100. Each customer orders a single product among 4 types of products. The demand of each customer is generated from three predetermined demand levels according to vehicle capacity, which is 16 tons. $U[1,8]$ indicates that demands are generated between 1 ton and 8 tons from a discrete uniform distribution. $\mathrm{U}[a, b]$ denotes that the random variable $U$ has the discrete uniform distribution with a finite number of equally spaced and equally probable 
outcomes with integer parameters $a$ and $b$, where $a<b$. One of the options which may occur is that the value of the demand generated from one of the demand levels is equal to the half capacity of a vehicle and the distribution range is low. This option is called lowdemand-low-variance setting. Considering demand value and distribution range, we can have two more options, high-demand-high-variance setting $(U[1,16])$ and high-demand-low-variance setting (U[4,12]). The fuel cost is assumed to be $\alpha=1.4 \mathrm{USD} / \mathrm{km}$ in all settings, while the fixed cost of using a vehicle is set at one of two levels, either USD 200 or USD 400. For the number of vehicles, the total demand is divided by the vehicle capacity to yield the first level of the parameter $V$. The second and third levels are taken as $V+1$ and $V+2$. For the multiple-trip extension, a maximum of two trips is assumed per vehicle per day. In the case of the split delivery, a customer's demand can be split among a maximum of two vehicles, and the splitting ratio is not less than $25 \%$. The coordinates of customers are generated over a grid $(-200000 \mathrm{~m}$, +200000 m) divided into 16 equal zones. To reflect a realistic scatter considering the regional demand, 12 low-density (HD) and 4 high-density (LD) zones are defined, where a single high-density zone can contain up to 4 times more customers than a low-density one. The number of customers in a low-density zone is obtained through $\left\lceil\frac{N}{28(=4 \cdot 4+12)}\right\rceil$ and customer locations are assigned to zones according to their capacities. The depot is at the origin $(0,0)$, as shown in Figure 5. Euclidian distances are used.

Ten instances are generated from each setting, totaling to 300 instances. Hence, a total of 900 runs was made for three models. All runs are performed on a PC with Intel@ Core ${ }^{\mathrm{TM}}$ i5-3360M CPU @ 2.80GHz and 8.00 GB RAM. Up to 15-customer problems could be
$(-200000,200000)$

(200000, 200000)

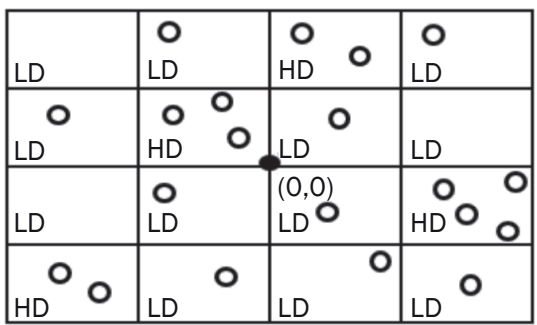

$(-200000,-200000)$

(200000, -200000)

Figure 5 - Zones and customers on the grid

solved to optimality using the base model, whereas 10-customer instances could be solved for other extensions.

Table 3 presents computational results for the base model, where each row represents ten instances of the same setting. Due to dominant fixed costs of vehicles as compared to fuel cost, optimal solutions try to keep the number of vehicles used at the minimum feasible number. The lowest average objective values belong to the $U[1,8]$ setting, since the highest number of orders can be loaded onto the same vehicle. The numbers of vehicles for $U[1,16]$ and $U[4,12]$ settings are similar. $U[1,16]$ has a higher variance; some vehicles can carry orders of many customers while some visit only one customer, increasing the routing cost. Hence, $U[1,16]$ instances yield higher objective values. As expected, low-demand-low-variance setting $(\mathrm{U}[1,8])$ has significantly higher computation times. Since vehicles can carry many orders, an increased number of assignment combinations increases CPU times in this setting. Following the reverse reasoning, $U[4,12]$ yields the fastest solutions. The combinatorial nature of the problem prevails as the number of customers increases, and the instances cannot be solved in reasonable times for more than 20 customers. The suggested heuristic algorithms, coded in C++ integrated with

Table 3 - Base model results for $N=10,15$

\begin{tabular}{||l|c|r|r|r|r|c|c||}
\hline & Avg. obj. & Avg. CPU [s] & Max CPU [s] & Min CPU [s] & Avg $K$ & Max $K$ & Min $K$ \\
\hline \hline N10_D1-16_FC400 & 4203.27 & 0.79 & 1.34 & 0.56 & 7 & 9 & 5 \\
\hline N10_D1-16_FC200 & 2903.27 & 0.65 & 1.31 & 0.30 & 7 & 9 & 5 \\
\hline N15_D1-16_FC400 & 6064.13 & 254.15 & 691.38 & 26.92 & 10 & 11 & 7 \\
\hline N15_D1-16_FC200 & 4224.13 & 493.73 & 2456.03 & 14.28 & 10 & 11 & 7 \\
\hline N10_D1-8_FC400 & 2609.85 & 1.16 & 3.52 & 0.28 & 4 & 4 & 3 \\
\hline N10_D1-8_FC200 & 1889.85 & 1.07 & 2.24 & 0.28 & 4 & 4 & 3 \\
\hline N15_D1-8_FC400 & 3551.98 & 330.34 & 686.00 & 9.28 & 5 & 6 & 4 \\
\hline N15_D1-8_FC200 & 2591.98 & 524.34 & 1187.32 & 12.11 & 5 & 6 & 4 \\
\hline N10_D4-12_FC400 & 4128.67 & 1.44 & 2.73 & 0.79 & 7 & 8 & 5 \\
\hline N10_D4-12_FC200 & 2868.67 & 1.62 & 2.05 & 0.95 & 7 & 8 & 5 \\
\hline N15_D4-12_FC400 & 5826.20 & 316.57 & 982.94 & 10.13 & 9 & 11 & 8 \\
\hline N15_D4-12_FC200 & 4099.75 & 356.22 & 934.25 & 8.63 & 9 & 11 & 8 \\
\hline \hline
\end{tabular}


Visual Studio Express, obtained solutions much faster. Solution quality performance of heuristics is shown in Table 4 for all 300 instances for each model.

Best UB gaps are computed as percentage gaps between optimal and heuristic solutions when optimal solutions are obtained. For the rest, lower bounds are used for comparison. Best LB gap \% columns present the gaps between optimal solution and the best lower bound. In our computations, we observed that LB3 consistently dominated the other two lower bounds for all three models when it could be computed. Therefore, Best LB Gap \% column lists the percentage gaps between the heuristic solutions and LB3 for 10-node and 15-node instances for the base model. However, for larger instances, obtaining a feasible solution from
CPLEX within hours was not possible, let alone within 5 minutes. For this reason, the gaps in Best LB Gap \% column are computed for larger instances using only the best of LB1 and LB2 as the lower bound. It should be noted that much higher gaps are observed immediately after this threshold. The increased gaps between the heuristic and Best LB for the larger instances can therefore be attributed not to the decreased performance of our heuristics for these instances but to the evident weakness of LB1 and LB2 as compared to LB3.

To better reveal this effect, a third column, LB Gap $\%$, is added for each variant, which presents percentage gaps between heuristic solutions and the best of LB1 and LB2. In other words, this column lists the

Table 4 - Performances of heuristics

\begin{tabular}{|c|c|c|c|c|c|c|c|c|c|}
\hline & \multicolumn{3}{|c|}{ Basic model } & \multicolumn{3}{|c|}{ Multiple-trip model } & \multicolumn{3}{|c|}{ Split-delivery model } \\
\hline & $\begin{array}{l}\text { BEST LB } \\
\text { GAP [\%] }\end{array}$ & $\begin{array}{l}\text { BEST UB } \\
\text { GAP [\%] }\end{array}$ & $\begin{array}{c}\text { LB GAP } \\
{[\%]}\end{array}$ & $\begin{array}{l}\text { BEST LB } \\
\text { GAP [\%] }\end{array}$ & $\begin{array}{l}\text { BEST UB } \\
\text { GAP [\%] }\end{array}$ & $\begin{array}{c}\text { LB GAP } \\
{[\%]}\end{array}$ & $\begin{array}{l}\text { BEST LB } \\
\text { GAP [\%] }\end{array}$ & $\begin{array}{l}\text { BEST UB } \\
\text { GAP [\%] }\end{array}$ & $\begin{array}{c}\text { LB GAP } \\
{[\%]}\end{array}$ \\
\hline N10_D1-16_FC400 & 0.00 & 0.00 & 15.98 & 0.00 & 0.00 & 23.99 & 2.19 & 1.21 & 13.97 \\
\hline N10_D1-16_FC200 & 0.00 & 0.00 & 23.09 & 0.00 & 0.00 & 31.17 & 3.06 & 1.01 & 21.46 \\
\hline N10_D1-8_FC400 & 0.00 & 0.00 & 20.65 & 0.00 & 0.32 & 37.96 & 0.00 & 0.22 & 22.41 \\
\hline N10_D1-8_FC200 & 0.00 & 0.00 & 31.31 & 0.00 & 0.40 & 40.86 & 0.00 & 0.31 & 34.01 \\
\hline N10_D4-12_FC400 & 0.00 & 0.00 & 21.14 & 0.00 & 0.62 & 27.88 & 6.59 & 1.50 & 13.82 \\
\hline N10_D4-12_FC200 & 0.00 & 0.00 & 28.99 & 0.00 & 0.80 & 35.27 & 4.77 & 1.45 & 21.23 \\
\hline N15_D1-16_FC400 & 0.00 & 0.00 & 22.58 & & 8.26 & 31.66 & & 17.14 & 19.94 \\
\hline N15_D1-16_FC200 & 0.27 & 0.00 & 31.00 & & 8.98 & 40.93 & & 23.34 & 29.25 \\
\hline N15_D1-8_FC400 & 0.08 & 0.14 & 20.39 & & 13.47 & 38.41 & & 14.02 & 23.44 \\
\hline N15_D1-8_FC200 & 0.18 & 0.52 & 30.66 & & 11.02 & 28.45 & & 19.24 & 36.73 \\
\hline N15_D4-12_FC400 & 0.07 & 0.00 & 25.84 & & 14.41 & 33.39 & & 14.03 & 17.87 \\
\hline N15_D4-12_FC200 & 0.00 & 0.00 & 35.10 & & 20.69 & 44.48 & & 23.42 & 29.31 \\
\hline N20_D1-16_FC400 & & 10.40 & 21.84 & & 9.80 & 13.86 & & 17.66 & 18.66 \\
\hline N20_D1-16_FC200 & & 12.36 & 29.39 & & 15.66 & 23.68 & & 25.95 & 27.60 \\
\hline N20_D1-8_FC400 & & 16.95 & 24.95 & & 25.07 & 27.15 & & 19.86 & 24.16 \\
\hline N20_D1-8_FC200 & & 24.91 & 36.86 & & 34.97 & 39.59 & & 30.37 & 36.45 \\
\hline N20_D4-12_FC400 & & 14.42 & 27.17 & & 19.46 & 19.84 & & 19.38 & 19.63 \\
\hline N20_D4-12_FC200 & & 17.86 & 35.66 & & 27.01 & 31.87 & & 29.31 & 29.81 \\
\hline N50_D1-16_FC400 & & 25.73 & & & 37.67 & & & 24.33 & \\
\hline N50_D1-16_FC200 & & 36.41 & & & 42.58 & & & 34.41 & \\
\hline N50_D1-8_FC400 & & 38.14 & & & 71.98 & & & 38.19 & \\
\hline N50_D1-8_FC200 & & 56.00 & & & 70.47 & & & 50.80 & \\
\hline N50_D4-12_FC400 & & 30.71 & & & 36.80 & & & 25.62 & \\
\hline N50_D4-12_FC200 & & 43.02 & & & 48.40 & & & 35.95 & \\
\hline N100_D1-16_FC400 & & 29.13 & & & 40.74 & & & 28.28 & \\
\hline N100_D1-16_FC200 & & 42.07 & & & 52.16 & & & 39.99 & \\
\hline N100_D1-8_FC400 & & 45.59 & & & 76.72 & & & 44.08 & \\
\hline N100_D1-8_FC200 & & 66.84 & & & 86.63 & & & 62.26 & \\
\hline N100_D4-12_FC400 & & 29.56 & & & 43.56 & & & 30.48 & \\
\hline N100_D4-12_FC200 & & 47.94 & & & 56.89 & & & 44.46 & \\
\hline
\end{tabular}



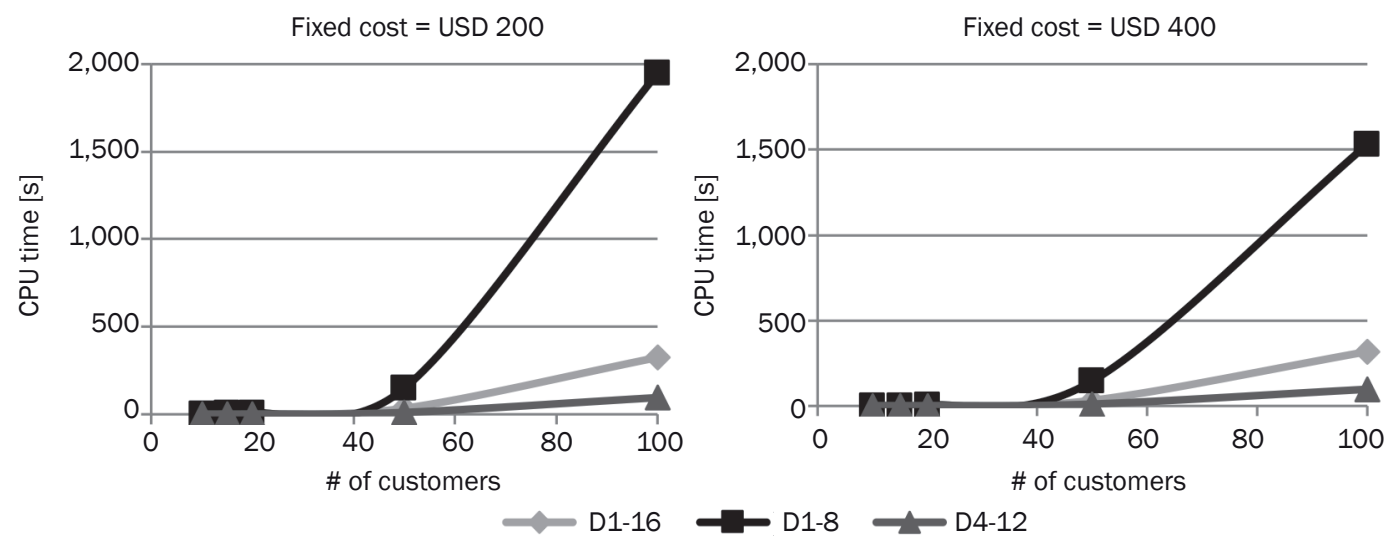

Figure 6 - Average time performance of heuristics for the base problem

percentage gaps when LB3 is not used. It can be clearly seen that, in the absence of LB3, the gaps would get much worse, including for the smallest problem instances.

The number of customers directly affects CPU time for the heuristics. Figure 6 shows the relation between the problem size and CPU times for the basic problem. U[1-8] setting for demand distribution has the highest CPU times, increasing parabolically after 50 customers. The reason is that the improvement phase of the heuristic algorithm tries to combine customer demands while minimizing the number of vehicles used. Since many customer demands can fit into a vehicle with low demand settings, finding a better route combination among the many customer locations increases. As expected, a lower fixed cost yields higher computation times due to the trade-off between routing and vehicle costs. Multiple-trip and split-delivery variants have similar patterns in solution times. When it comes to multiple trips, the maximum solution time is observed to be $2292 \mathrm{~s}$, while the average time (over all instances) is 1981. As might be expected, split delivery has the highest CPU times, going up to $3345 \mathrm{~s}$ for the largest instances, while averaging 2539 s over all instances.

Table 5 - Savings over the basic model

\begin{tabular}{||c|c|c|c||}
\hline $\begin{array}{c}\text { Fixed cost } \\
\text { [USD] }\end{array}$ & $\begin{array}{c}\text { \# of } \\
\text { customers }\end{array}$ & $\begin{array}{c}\text { Multiple-trip } \\
\text { model }\end{array}$ & $\begin{array}{c}\text { Split-delivery } \\
\text { model }\end{array}$ \\
\hline \multirow{4}{*}{400} & 10 & $36.56 \%$ & $2.61 \%$ \\
\cline { 2 - 4 } & 15 & $36.76 \%$ & $3.74 \%$ \\
\cline { 2 - 4 } & 20 & $36.95 \%$ & $3.96 \%$ \\
\cline { 2 - 4 } & 50 & $37.84 \%$ & $4.54 \%$ \\
\hline \multirow{4}{*}{200} & 100 & $37.23 \%$ & $4.79 \%$ \\
\cline { 2 - 4 } & 10 & $23.88 \%$ & $2.41 \%$ \\
\cline { 2 - 4 } & 15 & $23.45 \%$ & $2.61 \%$ \\
\cline { 2 - 4 } & 20 & $24.93 \%$ & $2.80 \%$ \\
\cline { 2 - 4 } & 100 & $24.98 \%$ & $3.43 \%$ \\
\hline \multirow{3}{*}{} & 50 & $25.90 \%$ & $3.83 \%$ \\
\hline
\end{tabular}

To illustrate the cost advantage of heuristic solutions, Table 5 presents the percentage of improvement of multiple-trip and split-delivery objective values over the basic problem.

It seems that the multiple-trip solutions can decrease the number of used vehicles considerably without violating the 8-hour shift limit; the average savings over the basic problem reach up to $38 \%$ when the fixed cost is high. The split-delivery approach, on the other hand, tries to decrease routing cost by splitting customer orders among vehicles, thereby resulting in relatively small, but still valuable savings.

\section{CONCLUSION}

In this study, we consider a vehicle routing problem with compartments under product incompatibility. A taxonomic framework was proposed for many variants of the VRP as a result of the extensive literature survey. In addition to the basic problem, the multiple-trip and split-delivery extensions are formulated. Since exact solutions could only be obtained for small instances of the three variants, heuristic approaches are developed for solving practical larger instances of the problem. Simplistic lower bounds are also developed for comparison purposes. While the solutions with heuristics for small-size instances could be obtained in milliseconds, CPU time increased as the number of customers increased.

Our initial numerical tests show that the extensions bring considerable savings when compared with the basic model. The operational decision of performing multiple trips per vehicle substantially decreases the number of vehicle usage, and in turn, the total fixed cost. Although the split-delivery approach decreased the overall cost of the basic model, it was not found to be as effective as the multiple-trip approach. The results indicate that the heuristic approaches developed in this study may be adapted and used by various companies that are dealing with these types of problems and want good solutions computed effectively in reasonable computing times. 
Developing more sophisticated algorithms that can yield better results, including metaheuristics, is one of the future research directions. In such a case, it is important to keep in mind the quality-time trade-off for practical applications, as well as the applicability and ease-of-use of the solution approach by industry professionals.

\section{BAHAR TASSAR, M.S. ${ }^{1}$}

E-mail: bahar.turantasar@gmail.com

DENIZ TÜRSEL ELiiYi, Prof. Dr. ${ }^{2}$

(Yazışmadan sorumlu yazar)

E-mail: deniz.eliiyi@bakircay.edu.tr

LEVENT KANDILLER, Prof. Dr. ${ }^{3}$

E-mail: levent.kandiller@yasar.edu.tr

${ }^{1}$ Ege Üniversitesi

İktisadi ve İdari Bilimler Fakültesi

İșletme Bölümü

35100, Bornova, İmir, Türkiye

2 İzmir Bakırçay Üniversitesi

Mühendislik ve Mimarlık Fakültesi

Endüstri Mühendisliği Bölümü

35665, Menemen, İzmir, Türkiye

3 Yaşar Üniversitesi Mühendislik Fakültesi

Endüstri Mühendisliği Bölümü

35100, Bornova, İzmir, Türkiye

\section{ÜRÜN KARIŞMAMA KISITLARI ALTINDA ÇOK KOMPARTIMANLI ARAÇ ROTALAMA \\ ÖZET}

Bu çalışma, bir aracın kompartmanlarında birbiriyle karışmaması gereken ürünleri içeren bir dağıtım problemine odaklanmıştır. Farklı müşteri taleplerini minimum lojistik maliyetiyle karşılamak için ürünler filodaki araçların farklı kompartmanlarında depolanır. Bu durum problemin Çok Kompartımanlı Araç Rotalama Problemi (ÇKARP) olarak modellenmesini gerektirir. Araç Rotalama Problemi (ARP) ve çeşitli varyantları hakkında geniş bir literatür olmasına rağmen, ÇKARP üzerine çok daha az araştırma bulunmaktadır. Illk olarak bu çalışmada ARP literatürü için yeni bir taksonomik çerçeve önerilmiştir. Buna ek olarak, temel ÇKARP ile birlikte problemin çoklu sefer ve bölünebilir sipariş uzantıları için kesin çözümler elde etmek amacıyla yeni matematiksel modeller önerilmiştir. Son olarak, üç problem varyantının daha büyük örnekleri için sezgisel algoritmalar geliştirilmiştir. Geliştirilen sezgisel yöntemlerin performansını daha büyük problem örnekleri için optimum çözümlere karşı test etmek amacılla bir alt sınırlama şeması da önerilmiştir. Hesaplamalı deneylerin sonuçları modellerin geçerliliğini ve algoritmaların gelecek vaat eden performanslarını göstererek raporlanmıştır.

\section{ANAHTAR SÖZCÜKLER}

Çok kompartımanlı araç rotalama problemi; karışamayan ürünler; bölünmüş dağıtım; çoklu sefer; matematiksel modelleme; sezgisel algoritmalar;

\section{REFERENCES}

[1] Dantzig GB, Ramser JH. The Truck Dispatching Problem. Management Science. 1959;6(1): 80-91.
[2] Lenstra J, Rinnooy KA. Complexity of Vehicle Routing and Scheduling Problems. Networks. 1981;11(2): 221-227.

[3] Reisman A. Management Science Knowledge: It's Creation Generalization and Consolidation. Westport CT: Quorum Books Publishing Company; 1992.

[4] Bodin L, Golden B. Classification in Vehicle Routing and Scheduling. Networks. 1981;11(2): 97-108.

[5] Desrochers M, Lenstra JK, Savelsbergh MWP. A Classification Scheme for Vehicle Routing and Scheduling Problems. European Journal of Operational Research. 1990;46(3): 322-332.

[6] Laporte G, Osman IH. Routing Problems: A bibliography. Annals of Operations Research. 1995;61(1): 227 262.

[7] Eksioglu B, Vural AV, Reisman A. The Vehicle Routing Problem: A taxonomic review. Computers \& Industrial Engineering. 2009;57(4): 1472-1483.

[8] Bin S, Fu Z. An Improved Genetic Algorithm for Vehicle Routing Problem with Soft Time Windows. Systems Engineering. 2003;21(6): 12-15.

[9] Chang TS, Wan YW, Tsang W. A Stochastic Dynamic Traveling Salesman Problem with Hard Time Windows. OOI European Journal of Operational Research. 2009;198(3): 748-759.

[10] Rais A, Alvelos F, Carvalho MS. New Mixed Integer-Programming Model for the Pickup and Delivery Problem with Transshipment. European Journal of Operational Research. 2014;235(3): 530-539.

[11] Goetschalckx M, Blecha CJ. The Vehicle Routing Problem with Backhauls. European Journal of Operational Research. 1989;42(1): 39-51.

[12] Oesterle J, Bauernhansl T. Exact Method for the Vehicle Routing Problem with Mixed Linehaul and Backhaul Customers, Heterogeneous Fleet, time Window and Manufacturing Capacity. Procedia CIRP. 2016;41: 573-578.

[13] Dror M, Trudeau P. Split Delivery Routing. Naval Research Logistics. 1990;37(3): 383- 402.

[14] Salhi S. The Integration of Routing into the Location-Allocation and Vehicle Composition Problems. [PhD thesis]. University of Lancaster; 1987.

[15] Lahyani R, Coelho CL, Khemakhem M, Laporte G, Semet F. A Multi-Compartment Vehicle Routing Problem Arising in the Collection of Olive Oil in Tunisia. Omega. 2015;51: 1-10.

[16] Kuo Y, Wang CC, Chuang PY. Optimizing goods assignment and the vehicle routing problem with time-dependent travel speeds. Computers \& Industrial Engineering. 2009;57(4): 1385-1392.

[17] Çetin S, Gencer C. Heterojen Araç Filolu Zaman Pencereli Eş Zamanlı Dağıtım-Toplamalı Araç Rotalama Problemleri: Matematiksel Model. International Journal of Research and Development. 2011;3(1): 19-27.

[18] Yakıcı E, Karasakal O. A min-max vehicle routing problem with split delivery and heterogeneous demand. Optimization Letters. 2013;7(7): 1611-1625.

[19] Bullnheimer B, Hartl RF, Strauss C. Applying the Ant System to the Vehicle Routing Problem. In: Voss S, Martello S, Osman IH, Roucairol C, editors. Meta-Heuristics: Advances and Trends in Local Search Paradigms for Optimization. Springer/Kluwer; 1997. p. 285-296.

[20] Lee T, Ueng J. A Study of Vehicle Routing Problems 
with Load-Balancing. International Journal of Physical Distribution \& Logistics Management. 1999;29(10): 646-658.

[21] Corberan A, Fernandez E, Laguna M, Marti R. Heuristic Solutions to the Problem of Routing School Buses with Multiple Objectives. Journal of the Operational Research Society. 2002;53(4): 427-435.

[22] Han H, Cueto EP. Waste collection vehicle routing problem: literature review. Promet - Traffic \& Transportation. 2015;27(4): 345-358.

[23] Cordeau JF, Laporte G. A Tabu Search Algorithm for the Site Dependent Vehicle Routing Problem with Time Windows. INFOR. 2001;39(3): 292-298.

[24] Letchford AN, Eglese RW. The Rural Postman Problem With Deadline Classes. European Journal of Operational Research. 1998;105(3): 390-400.

[25] Derigs U, Gottlieb J, Kalkoff J, Piesche M, Rothlauf F, Vogel U. Vehicle Routing with Compartments: Applications, Modelling and Heuristics. OR Spectrum. 2011;33(4): 885-914.

[26] Rabbani M, Farrokhi-asl H, Rafiei H. A hybrid genetic algorithm for waste collection problem by heterogeneous fleet of vehicles with multiple separated compartments. Journal of Intelligent \& Fuzzy Systems. 2016;30(3): 1817-1830.

[27] Archetti C, Jabali OM, Speranza G. Multi-period Vehicle Routing Problem with Due dates. Computers and $\mathrm{Op}$ erations Research. 2015;61: 122-134.

[28] Kendall DG. Stochastic Processes Occurring in the Theory of Queues and their Analysis by the Method of the Imbedded Markov Chain. The Annals of Mathematical Statistics. 1953;24(3): 338-354.

[29] Van der Bruggen L, Gruson R, Salomon M. Reconsidering the Distribution Structure of Gasoline Products for a Large Oil Company. European Journal Operational Research. 1995;81(3): 460-473.

[30] Avella P, Boccia M, Sforza A. Solving a Fuel Delivery Problem by Heuristic and Exact Approaches. European Journal of Operational Research. 2004;152(1): 170-179.

[31] Suprayogi, Komara S, Yamato H. A Local Search Technique for Solving a Delivery Problem of Fuel Products. Proceedings of the $2^{\text {nd }}$ International Conference on Operations and Supply Chain Management, 2007 May 18-20, Bangkok, Thailand.

[32] El Fallahi A, Prins C, Wolfler C. A Memetic Algorithm and a Tabu Search for the Multi-Compartment Vehicle Routing Problem. Computers \& Operations Research. 2008;35(5): 1725-1741.

[33] Mendoza, JE, Castaniera B, Guéreta C, Medagliab AL,
Velascob N. A Memetic Algorithm for the Multi-Compartment Vehicle Routing Problem with Stochastic Demands. Computers \& Operations Research. 2010;37(11): 1886-1898.

[34] Surjandari I, Rachman A, Dianawati F, Wibowo RP. Petrol Delivery Assignment with Multi-Product, Multi-Depot, Split Deliveries and Time Windows. International Journal of Modeling and Optimization. 2011;1(5): 375-379.

[35] Benantar A, Oufi R. Optimization of Vehicle Routes: An Application to Logistic and Transportation of the Fuel Distribution. Paper presented at: $9^{\text {th }}$ International Conference on Modeling, Optimization \& SIMulation, 2012 June 8, Bordeaux, France.

[36] Asawarungsaengkul K, Rattanamanee T, Wuttipornpun, T. A Multi-Size Compartment Vehicle Routing Problem for Multi-Product Distribution: Models and Solution Procedures. International Journal of Artificial Intelligence. 2013;11(A13): 237-256.

[37] Coelho LC, Laporte G. Classification, models and exact algorithms for multicompartment delivery problems. Operations Research. 2015;242(3): 854-864.

[38] Abdulkader MMS, Gajpal Y, EIMekkawy TY. Hybridized ant colony algorithm for the multi compartment vehicle routing problem. Applied Soft Computing. 2015;37: 196-203.

[39] Koch H, Henke T, Wascher G. A Genetic Algorithm for the Multi-Compartment Vehicle Routing Problem with Flexible Compartment Sizes. University of Magdeburg. Working Paper No. 04/2016, 2016.

[40] Alinaghian M, Shokouhi N. Multi-Depot Multi-Compartment Vehicle Routing Problem, Solved by a Hybrid Adaptive Large Neighborhood Search. Omega. 2018;76: 85-99.

[41] Kandiller L, Eliiyi DT, Taşar B. A Multi-compartment Vehicle Routing Problem for Livestock Feed Distribution. In: Dörner K, Ljubic I, Pflug G, Tragler G. (eds) Operations Research Proceedings 2015, 1-4 September 2015, University of Vienna, Austria; 2017. p. 149-155. Available from: doi:10.1007/978-3-319-42902-1_20

[42] Mladenović N, Hansen P. Variable neighborhood search. Computers \& Operations Research. 1997;24(11): 1097-1100.

[43] Clarke G, Wright J. Scheduling of vehicles from a central depot to a number of delivery points. Operations Research. 1964;12(4): 568-581.

[44] Ho W, Ji P. Component scheduling for chip shooter machines: A hybrid genetic algorithm approach. Computers \& Operations Research. 2003;30(14): 2175-2189.

[45] Glover F, Lagua M. Tabu search. MA: Kluwer Academic Publishers; 1997. 